\title{
BUILDING BRIDGES: \\ EXPLORING GENDER THROUGH PHOTOGRAPHIC PRACTICE
}

\author{
JENNIFER O'LEARY \\ Monday, March 6, 2006
}

\begin{abstract}
:
This project is a visual expression of my observations about gender within western culture. My photographic practice is conducted within and mediated by significant beliefs about gender and, in turn, provides ideological support for how I relate to society. Acknowledging that I photograph from a female perspective I photographed both male and female subjects of different genders and races using a $35 \mathrm{~mm}$ camera with a wideangle lens. I captured images that helped me reflect on my own practice as a photographer. My images can be viewed as individual photographs or as a set. Factors, such as my cultural background, social status, religious beliefs, and level of comfort with my own sexuality, influenced my photographic practice and so will inevitably affect how viewers respond to my images. How I feel about identity construction permeates through out my image making process. As a photographer in the Ryerson University and York University joint program of Communication and Culture exploring different theoretical frameworks undoubtedly affected my studio practice as I gained more knowledge and became more self-reflective. I accept as photographer that my images will not have a fixed meaning but I do intend them to evoke feelings.

Since I discovered Henri Cartier-Bresson's work as a young teenager I have always had a profound respect for his abilities and his methodology. Although I would never begin to align my work with a master photographer with regards to quality I have always aspired to his greatness. Robert Frank and Eugene Richards also have inspired me during this Masters project. My more recent appreciation of their work reinforces my belief that there will always be a place for striking 'documentary' style photographs taken on film and printed on fiber based paper by the hand of one whom feels the call of the traditional darkroom.
\end{abstract}




\section{Why Photography?}

I chose to enter the Ryerson joint program in Communication and Culture with York University as it was interdisciplinary and I wished to explore theoretical frameworks that were new to me while having the opportunity to benefit from professional development opportunities. The two areas that I chose for my specializations were Media and Culture and Technology in Practice: Applied Perspectives. Through my progression in the program I began to slowly focus my research and course work towards areas of theory and professional practice that were of personal interest to me. Visual culture, art education, gender, identities, sexuality issues, and photographic theories are areas that had emerging themes of interest to me. During the program no matter how interesting a course was and the availability of a corresponding direction in which I could research towards a written thesis, I always felt intrinsically linked to fulfilling my program requirements by completing a masters project rather than a written thesis. As Henri Cartier-Bresson so eloquently articulated in his book The Mind's Eye, "In photography, as elsewhere, the instant is its own question and at the same time its own answer. What excites and drives me in photography is the coincidence of gesture and spirit" (CartierBresson 86). My photographic practice is conducted within and mediated by significant beliefs about gender and, in turn, provides ideological support for how I relate to society. Increased awareness to sexuality studies and lesbian and homosexual writings has caused me to be more self-reflective concerning my behaviour and attitudes. Questioning how one interprets and accepts gender led me to read canonical texts from often competing viewpoints. Reading different theorists from feminist and lesbian movements to queer theory allowed me to approach their assertions from the perspective of a photographer, 
woman, and gendered female. In 'Beyond Binaries: Depolarizing the categories of Sex, Sexuality and Gender', Judith Lober presents powerful arguments for the need to split what is usually conflated as sex/gender or sex/sexuality gender into three conceptually distinct categories; sex (or biology, physiology), sexuality (desire, sexual preference, sexual orientation) and gender (social status, sometimes with sexual identity): "Each is socially constructed but in different ways. Gender is an overarching category, a major social status that organizes almost all areas of social life" (Lober 146). If gender is a social construction which has played a very important role in our social and political makeup it is in no way uniform. It varies across cultures, regions, and nationalities. One just has to think about the friction between the west and the Middle East not only along political and economic lines but focused around belief systems regarding the rights of women. The social realities for women vary greatly country to country within that region. How then does gender identity influence how photographic practice is conducted or how photographs made in one culture are viewed by another? Some thinkers would indeed assert that "an equally, if not more, interesting question is how much sex and sexuality influence how people see photographs" I respect that position but it was not the focus of my project. I chose to deal with one of Judith Lober's three terms for this project for I felt attempting to engage in all three and do so in a way that serves none (Elder). I also felt that with the 'documentary style' that I was employing that it fit best with my interests. 
Acknowledging that I photograph from a female perspective I photographed both male and female subjects of different genders and races using a $35 \mathrm{~mm}$ camera with a wideangle lens. I captured images that helped me reflect on my own practice as a photographer. Upon completion of the photo-shoots, I edited the images and printed a series that are exhibition quality. The images can be viewed as individual photographs or as a set. The purpose is to invite viewers to interpret the images without my textual commentary, yet, if they desire a textual guide I am willing to provide one. Factors, such as my cultural background, social status, religious beliefs, and level of comfort with my own sexuality, influenced my photographic practice and so will inevitably affect how viewers respond to my images. How I feel about identity construction permeates throughout my image making process. As a photographer in the joint program of Communication and Culture exploring different theoretical frameworks undoubtedly affected my studio practice as I gained more knowledge and became more self-reflective. Images I created at the beginning of my project directly influenced how my ideas began to take shape and the process of creating the final images was a revealing one. According to Sally Hagaman, a scholar of feminist theory in aesthetics and art education, "genders are the political constructions of what it means to live in a world where we are not merely human, but always man or woman. Genders are several. Genders are socialized. Gender is how a culture expects and tries to ensure that men act a certain way and women another, or a gay man this way and a lesbian that way" (Barrett 163). Gender in a hierarchical society can be very constraining. In a nonhierarchical society, gender might merely be a matter of choice. One is not born a feminist -- one chooses to become one. All women are not feminists, and all women do not make feminist art; nor do all 
feminists make feminist art, although feminists refuse to believe that art and politics are separate (Barrett 164).

The creative process of photography from which I explore or communicate a position has always seemed the better route for me, yet one that I have struggled against in the past. My desire to improve as a photographer, yet also make a living while fulfilling my obligations as a secondary school arts educator has created a feeling of discombobulation; feeling as if I am an intruder in both worlds. I feel disloyal to my artistic self as I often feel obliged to spend more time on my teaching as I am paid for it and have young students whose education I am partially responsible for; at the same time I feel like a phony not truly devoted to the field of teaching, never planning to have become a teacher, and preferring to refer to myself as a 'facilitator' amongst my students. Reading Robert Adams' writings in Why People Photograph resonated with me as a photographer, educator, and conflicted artist. It was as if Adams was speaking to my soul for he articulates what I often struggle to relay: Why do I photograph? Why am I drawn to studying Media and Culture and Technology in Practice? Simply put, because I feel compelled to. 


\section{On Being a Photographer}

As a photographer, only seventeen years into my craft, I still consider myself a novice to photography. My first recollections of my love affair with photography began upon purchasing my first Nikon-a second hand FG. Although I was just twelve years old I felt a sense of empowerment and intoxication when I held my first camera and framed my first subjects.

Foucault believed "power does not function in the form of a chain - it circulates. It is never monopolized by one centre. It is deployed and exercised through a net-like organization (Foucault, 1980, 90). This suggests that we are all, to some degree, caught up in its circulation—oppressors and the oppressed. Males and females are both equal in that they both are oppressor and the oppressed, at different times. "Power is not only negative, repressing what it seeks to control. It is also productive. It "doesn't only weigh on us as a force that says no, but ...it transverses and produces things, it induces pleasure, forms of knowledge, produces discourse. It needs to be thought of as a productive network, which runs through the whole social body (Foucault, 1980, 119). Perhaps the power I feel when I photograph is part of this circle. For me it is a productive power, one that allows me to explore ideas that are interesting to me. I agree that serious photographers, "may or may not make a living by photography, but they are alive by it" (Adams 14). Photography has been my route to self-exploration and constructing my identity. When I frame a scene with my camera viewfinder I feel like Cartier-Bresson; my camera is like a "sketchbook, an instrument of intuition and spontaneity, the master of the instant which, in visual terms, questions and decides simultaneously" (CartierBresson 45). I never feel like I know exactly what I will achieve, but sometimes I sense 
that I have captured the shot I was unknowingly waiting for at the moment I pressed the shutter release button.

Even renown photographers who are members of Magnum feel that there is often an uncertainty when a photographer is attempting to capture an image, one is never able to plan in entirety for what might unfold, "there is a lot of luck in capturing a significant picture, but the good photographers cut down the waste and make the shot far more likely. When I am looking for pictures I instinctively sense situations that might contain good shots. I then latch on to the situation and start shooting. Sometimes that action will build up into a climax in about six to ten shots, and then drop away" (Hurn 41).

Throughout the entire shooting part of the project I was always nervous as to whether I would capture what I was hoping for. Hurn believes that, "very often the difference between an average photographer and a really fine photographer is this willingness to admit doubt, that he/she is not at all certain that he/she has got it. The fine photographer says, in effect: Well that's a pretty good effort but I am willing to admit that many little subtleties of camera position, which I cannot pre-see, might make the difference between an adequate image and a good one" (Hurn 40). In my experience, I would continue to take more photographs just in case some other angle would work better and allow me potentially more flexibility in the darkroom. The action in a shot can build up slowly, but abruptly end and one can never recreate the moment in the same way so a good photographer must be always ready and always watching. 


\section{Methodology}

My methodology for this project involved myself as photographer constructing a dialogue/relationship with my subject(s) and methodically choosing the technical devices that allow me to capture the final photographic image. I chose to photograph almost all my work with a deep depth of field and all using 3200 ISO film for I did want a more grainy film than I would normally use. I also chose to have the scenes as focused as possible because where the subject(s) were was just as important as what they were engaged in. I intended to create images with many layers of meaning although at first glance they may look no more than a well-lit snapshot. Capturing the moment and choosing in that instant how to frame what I was witnessing was imperative to my process because part of how I see and frame my work is reflective in my work.

When photographers get beyond copying the achievements of others, or just repeating their own accidental first successes, they learn that they do not know where in the world they will find pictures. Nobody does. Each photograph that works is a revelation to its supposed creator. Yes photographers do position themselves to take advantage of good fortune sensing for instance when to stop the car and walk, but this is only the beginning (Adams 15).

I accept as photographer that my images will not have a fixed meaning but I do intend them to evoke feelings. During this photographic project I was very influenced by competing theories that I had read as part of my course work during the joint program in Communication and Culture. Within my past photographic work I have photographed a variety of subjects but always kept returning to representing bodies and environments. My work became a bit more collaborative over time, but still very self-directed. I enjoy questioning dominant ideology using photography as my tool. I also am drawn to photographing the human form, most often male, as a means to explore the body as a 
series of geometric forms. "Representing the body that way results from an effort to substitute a form of pleasure, the pleasure of geometric design, for another much more troubled sort of experience that is a mixture of the pleasures of desire (including those of voyeurism) with the delight in human/self-knowledge. The horror of the abject and the terror of that over which threatens to go beyond our control (the erotic) and the recognition of humans' vulnerability" (Elder) is a perspective to explore. I believe at this time in my development at a photographer I exchange formal pleasure for the human experience Elder alludes to as I still consider myself a novice photographer. With more time, maturity, and comfort with my own work I may explore this relationship. Currently, I rarely enter photographic experiences with an exact idea of what I hoped to achieve; the experience is more about learning and exploration. There has always been a pleasure in viewing my subject in a less literal way and having the ability to secure the images I best feel represent what I see through my camera lens.

I entered into my studio component with an idea of what I wanted to achieve, but knew full well that I am the type of photographer who must let my intuition lead me. The desire to explore identity construction through photography resulted in my request to photograph some subjects that I knew quite well and others that I would consider near strangers. I selected each subject specifically because they reflected my focus for my MA project through photographic practice. I did not want to control the settings in which I photographed my subjects, so I chose to let the subjects' routines dictate the locations. Although I had a few preconceived ideas for shots I also wanted to be open to capturing moments where I had little control with who my subjects were interacting with 
or what they were choosing to do. I was creating interpretative photographs, which are "personal and subjective interpretation, more like poetry than a scientific report. They are usually fictional and often use the 'directorial mode' of photography defined by A.D. Coleman as one in which the photographer caused something to take place which would not have occurred had the photographer not made it happen" (Barrett 70). They may appear as if they are documentary in style but a document is unbiased, non-judgmental, objective, factual evidence. And of course, no photograph I make comes close to this notion (Hurn 25). Like Hurn, I do not claim that the pictures I take are of some objective or definitive truth but are what I saw and felt at the time the pictures were made (Hurn 26). Maintaining this belief allows me to revisit my images and look at them closely to see what I was thinking both consciously and feeling intuitively when I was constructing and capturing the images.

When I was photographing Fabio Persico (bi-sexual identified) and Vanessa Leblond (lesbian identified) with their friends at Woody's on Church Street in Toronto I asked permission of the owner prior to documenting their evening in the bar. The owner had no problems with me photographing in his establishment but was adamant that I not photograph any of the other patrons without their consent, as some patrons would not want themselves captured on film in a gay bar. I acquiesced to his terms even though it did impact some of my ability to capture moments I witnessed. However, I accepted the limitations because I respected the sensitive nature of where I was photographing and the right of the other patrons' privacy. 
During my undergraduate degree in Image Arts I began exploring the concepts of gender identity and masculinity using a model that I had become comfortable with and, in my opinion, represented the iconic male. I was not commenting on power structures rather, posing questions through my imagery that I hoped would cause people of both genders to contemplate identity. The work was well received and even as I moved onto other projects the ideas and these images have remained in the back of my mind. I have never chosen to create work from an overtly feminist standpoint, for I prefer to have my work viewed not based on my gender but on the images. This may be a naïve and impossible intention, but one that I still hold on to. Politically correct sexuality is a paradoxical concept. One of the most deeply held opinions in feminism is that women should be autonomous and self-directed in defining their sexual desire, yet when a woman says "This is my desire," feminists rush in to say, "No, no, it's the prick in your head; women should not desire that act" (Nestle 234). As Nestle rightly asserts in her essay "The Fem Question', "we do not yet know enough at all about women-any women and desire". While I acknowledge that I photograph from a female perspective I do not feel this position from which I photograph is a hindrance. I do not think that is the only perspective in which to view my work but if people insist on categorizing my work as 'female' it does not bother me in the way it might others for I think the quality of an image transcends categorical limits.

Framing is a transformative element for "a photograph has edges the world does not. The edges separate what is in the picture from what is not" (Shore 28). With certain shots I was very deliberate in the framing I was after as I wanted to guide the viewer to what I 
was seeing at the time I was capturing an image. Other times I would be a witness to something unfolding that I had no way of planning for. A person or object would penetrate the frame as I was focusing solely on what was immediately around the subject not concerned as much with composition or aesthetics but with capturing the moment that was fleeting. For some images the edges provide both visual and contextual information. "For some pictures the frame acts passively. It is where the picture ends. The structure of the picture begins within the image and works its way out to the frame...the frame energies the space around the figures" (Shore 31 ). In the majority of my work when lighting permitted I aimed for as deep a depth of field as possible. I wanted the viewer to be able to see as much information in the foreground and the background as possible. "Pictures exist on a mental level that may be coincident with the depictive level---what the picture is showing---but does not mirror it. The mental level elaborates, refines, and embellishes our perceptions of the depictive level. The mental level of a photograph provides a framework for the mental image we construct of (and for) the picture" (Shore 55). Prior to reading Shore's book 'The Nature of Photographs' I intuitively was aware of the factors such as vantage point, time, and focus among others. "Focus is the bridge between the mental and depictive levels: focus of the lens, focus of the eye, focus of attention, focus of the mind (Shore 56). 


\section{Process}

When I construct a scene with my camera lens I am looking or viewing my subject in a deliberate fashion. I am constructing a dialogue/relationship with my subject and methodically choosing the technical devices that allow me to affect the final photographic image. What I chose to emphasize, what I chose to keep in focus, what aperture I used, what printing technique I employed, all factor into creating the photographic print. However, the image that is produced does not have a fixed meaning. When I look through my lens I feel a sense of control, in that I know that I can capture the moment, the essence of my interpretation of the scene with patience and some frames of film. This does not have to have negative connotations. As a photographer I am a curious observer of everyday reality and utilize my spectator's gaze quite often as a starting point for photographic projects. I often survey a scene and imagine how I would expose an authentic reality that often may be below the surface layer by photographing the scene and the subjects. I construct meaning between the scene and myself. An average person who views my work most likely will see the aesthetically pleasing images 'pictorial' in style or 'documentary' but may miss the questions I am trying to pose through my imagery because they are constructing their own meaning separately. "When photographers take pictures, they hold mental models in their minds, models that are the result of the prodding of insight, conditioning, and comprehension of the world" (Shores $65)$.

The need for "historical specificity in conceptualizing masculinities" is altering the tired assertion that men are always the dominant sex, always holding onto the power. A new 
form of masculinity has evolved since the late 1980s and this has contributed the acknowledgement that women can gaze at men in a voyeuristic or fetishistic relation without having to identify with the subject. "Voyeuristic looking is marked by the extent to which there is a distance between spectator and spectacle, a gulf between the seer and the seen. This structure is one which allows the spectator a degree of power over what is seen" (Neale 331). Neale maintains that masculinity both inside and outside of cinema, has been "so rarely discussed" because "femininity is, by contrast a mystery" perhaps it is up to women and homosexual men to present alternate versions of the expected to create an imbalance and promote critical inquiry into gender issues. Narratives of the self, the practices of the self for men have evolved and broadened so that practices such as grooming and certain techniques of care that would have in the past been attributed as feminine are now gender neutral. There is a more expanded formulation of agency for both men and women. Photography as a representational system uses images to communicate photographic meaning. The meaning of an image created in this time is altered by the way both genders see themselves and their partners. Discourse is a way to refer to or construct knowledge about a particular topic or practice; it provides ways of talking about forms of knowledge and conduct associated with, a particular topic, social activity or institutional site in society (Hall 6). Discursive formations are historically specific as well as cultural. They did not and could not meaningfully exist outside specific discourses, i.e. outside the ways they were represented in discourse, produced in knowledge and regulated by the discursive practices and disciplinary techniques of a particular society and time (Hall 47). 


\section{A More Accurate Method of Communication}

“To take photographs means to recognize--simultaneously and within a fraction of a second-both the fact itself and the rigorous organization of visually perceived forms that gives it meaning. It is putting one's head, one's eye, and one's heart on the same axis" (Cartier-Bresson 1). I cannot achieve this same truth with writing. When I write I rarely find that I feel as confident about what my head and heart truly believes. Words get in the way; someone always can articulate it better, and I find I need to constantly qualify or explain my writing. When I create photographic images I can clearly communicate on the same axis that Cartier-Bresson refers to in his book The Mind's Eye. The process of creating an image and the need to write about it at length has always been a difficult exercise for me. Unless I am speaking to another photographer and can reference other photographers or movements in photography I often feel as though I fall short during the communication process or possibly better said not properly understood. I have always felt that my photographic work speaks more clearly than I am able too. I have the ability to intuitively layer an image with the method in which I capture my 'decisive moment'. "C.S. Lewis admitted, when he was asked to set forth his beliefs that he never felt less sure of them than when he tried to speak of them. Photographers know this frailty" (Adams 35). I feel sure of how I frame my images. I rarely doubt my work from a composition or aesthetics point of view for I feel confident in the ability to capture my feelings using a camera, but falter when am I asked to articulate the 'why' as part of my methodology. 
Photographers seemed so strikingly unable to write at length about what they had made, in fact, that I came to wonder if there was any exception at all, a single case where an artist's writing did not end up making a picture smaller, less complex, less resonant, less worth of comparison with life...Part of the reason that these attempts at explanation fail, I . think, is that photographers, like all artists, choose their medium because it allows them the most fully truthful expression of their vision. Other ways are relatively imprecise and incomplete (Adams 32).

Happening upon Adams' writing, thanks to Don Snyder, almost felt freeing for as I read his essays it was as though Adams was articulating my thoughts which I had while working on my craft for the last seventeen years. I find myself often justifying the apparent straightforwardness of my work because without using a lot of fancy techniques and no digital photography I still create multi-layered images. I like to think of my photographs as images that can be appreciated from a quick read or studied and unpacked for symbolism and visual devices much like a short story could be (Adams 32). I do not think it is always necessary to know what the photographer meant to do or wishes to communicate in its entirety for there is a level of intuitiveness to good photographers and is enigmatic. However, I do not object to secondary apparatuses for they can aid those who attempt to seek or appreciate work. But even that does not arrive at a satisfactory explanation. I think visual communication is an area that is under explored and researched. As a method of communication we tend to place most emphasis on the written word as a means of clearly conveying a point of view. For those that respond to the written word and are not photographers a guide into the mind or soul of the photographer can be helpful for learning to appreciate a photographer's work. An ability to contextualize the work and unpacking the potential meaning of a photographer's images helps make the work more accessible to them. Often young students may not 
appreciate photographs that would otherwise be seen as straightforward. I think most photographic artists on some level consciously or unconsciously acknowledge that there are others that may view their work and not understand the visual language in which they are communicating. In this regard I do not have a strong aversion to seeing text accompany photographic images. I think that as viewers in a gallery setting or in the context of looking at a photographic book we are not obliged to read the text if we feel that is will somehow ruin the appreciation of the work. Eugene Richards' work is most usually accompanied by an ample amount of text and it does not hinder how I appreciate his images.

I have always maintained, even if it is a politically incorrect view point among my colleagues that one either has 'the eye' for photography or one does not. I maintain that I cannot teach photography students to truly 'see'; one either has it or one does not. I can facilitate those who have it to develop it and create technically more correct photographs, but this is where my responsibility stops. I can teach an interested student how to use the elements and principles more efficiently in their photographs but if they do not have the 'eye' their work will always be lacking even if they follow all the 'rules and guidelines' laid out in the how to photography books. "As with all art, it is an issue to be decided in terms of the way the art operates (technique) and what the art says (content), but these factors are inextricably bound, and never in exactly the same way in any two pictures, so that rules are out of the question" (Adams 77). Just as I maintain this position and have reinforced it each semester when I teach those at the secondary level new to photography, so, too, do I believe that some viewers lack the patience to see what is in an image and 
some photographers do not want their work to be too straightforward for they feel on some level it lessens the meaning. I create my images primarily for myself, but with the knowledge that they are going to be viewed by both critical minds and by disinterested viewers. I am never oblivious to the idea that photographs I create will be seen by an audience of some sort. The only work that I am interested in exhibiting is noncommercial personal work, therefore, I understand that some of my work will be well received and speak to some people and others will not understand or appreciate my form of communication. I communicate through this medium because it satisfies my need to work through subjects that interest me. "Even if most artists work first from a sense of obligation to themselves, however, they usually believe that if they answer their private demands they will in the course of doing so also fulfill their duty to others. It is a risky and arrogant proposition, but it is an attitude as common to the calling as is the brittle behavior of its adherents" (Adams 77). As I evolve and mature as an photographer I believe my work will change as well and have even more impact.

\section{Utilizing Inspirations}

Since I discovered Cartier-Bresson's work as a young teenager I have always had a profound respect for his abilities and his methodology. Although I would never begin to align my work with a master photographer with regards to quality; I have always aspired to his greatness. Robert Frank and Eugene Richards also have inspired me during this MA project. My more recent appreciation of their work reinforces my belief that there will always be a place for striking 'documentary' style photographs taken on film and printed on paper by the hand of one whom feels the call of the traditional darkroom. The 
strength of Frank's photographs stem from the clarity of his photographer's eye and little manipulation beyond vantage point and timing.

After reading "Shaken not Stirred: The Cocktail of Visual Culture" by Pauline Terreehorst, I was very interested in some of the points she raised concerning photography and visual culture; "It appears that, under the influence of the urge for legitimating and from economic necessity, pressure is being put on from all sides not only to abolish the distinction between photography, film and the new media, but also to classify all of them under the rubric of visual arts" because of this "the appeal that images make to the individual, and to the individual motives of a viewer" seem to hardly come up for consideration anymore (Terreehorst 28-29). If the whole of visual culture is treated as visual art it becomes problematic. So many elements of everyday life have by now become so permeated by what we have come to call "visual culture". "How we make love, how we dress, how we live, work, shop, relax and move: it is all at some moment connected with photography and film" (Terreehorst 24).

As a photographer, I believe that the differences between photography and film should be allowed to remain; not be carelessly blended into loosely defined categories. I agree with Terreehorst when she maintains that "photography differs from film in that it is the art of the frozen image: it is always motionless. That offers the possibility of giving every detail within the frame an extra significance. It leads to different forms of presentation from those that are conventional in the visual arts," (Terreehorst 31). Even if a series of photographs are arranged in a narrative sequence, they still do not constitute film, because the photographs can be viewed in any sequence. 
Recognizing that meaning is dependent on, for instance, shared cultural codes (which are also understood to be historically located and subject to change), audiences should no longer be thought of as passive receivers (Harley 209). Anchorage a term used by Harley is what is suggested to allow viewers of images to choose between what could be a confusing number of possible denotative meanings. The viewer of a photograph is active in the meaning-making process, bringing with them cultural experiences, discourses and ideologies for the process of making sense (Harley 209).

In 'When Men Meet: Homosexuality and Modernity' Henning Bech produces a very vivid explanation of the homosexual male gaze. Thorough his narrative he allows others not of this world to peer inside it. He maintains that the homosexual is equipped with a gaze as they are "virtuosos at using the gaze; it can discern almost imperceptible signs; it can fine-tune and flit around endlessly different ways" and that "it is impossible to be homosexual without having a gaze" (Bech 108). While reading his descriptions of the various types gay men gaze I saw similarities to how I operate as a female whose passion is photography. I am always gazing at potential subjects even when my camera is not at hand. Like Bech can find "pleasure, excitement, affirmation", I, too identify (Bech 106). I can use my gaze as a means of seduction but also as a means Bech would term as purely fetishistic; "the gaze wants to caress buttocks and bulges, it wants to take its pleasure through the other person but not with him, and to keep its pleasure to itself, a pure treat for the eyes. The surface is far too interesting to be spoilt by any interior" (Bech 107). Bech also genders the gaze. Would being an identified heterosexual gendered female photographer make me ineligible to possess the ability to gaze in a manner that a 
homosexual man can? Would feminists negate this ability? Elder maintains that "many visual artists have used tactile forms in an effort to close this distance and to engender a relationship between subject and image that is less voyeuristic." Perhaps this is the bridge that is necessary to acknowledge characteristics of some while not negating similarities between others.

In the Netherlands two organizations, The Netherlands Foto Instituut and the Mondriaan Foundation worked together on a project 'Constructing Identity' for a period of a year in 1996. The aim was to create photography to inform the public about a variety of topics in danger of being overlooked. Discourse between the Netherlands Photo Instituut and the Mondriaan Foundation led to the organization of a series of commissions under the general title of PhotoWork(s) with a view to highlighting the role of photography in the debate on social issues. PhotoWork(s) likened their mandate to investigative journalism by suggesting the term investigative photography - a fundamental photographic research in which an attempt is made to penetrate to the heart of the subject under scrutiny. A committee was asked to propose a theme that forms an important concern in our society. The committee came up with the topic 'Constructing Identity'. The departure point was the realization that in modern society people often shape their own identity. More than previously, and that, this occurs independently of their origins, cultural, and religious background or gender. Through nominations and open application procedure 76 proposals were evaluated and three photographers and three writers were selected (Roodenburg 6). 
The project was an inspiration to me for "the photographer investigates and portrays social developments and situations from his or her own world view, in order to influence people's notions and images of society. The intention is crucial here and it requires deliberate reflection on the role of photography in culture, particularly visual culture and on how people perceive the medium. Photographers choose the methods and techniques they need to achieve their aims, while realizing that these choices are coloured by their own background and view of the world. In doing so they also realize that the context in which the work will be seen, and the background of those who see it, will determine how the work is interpreted. The intention of the work, the subject, the method and technique are all in the photographer's control; a fourth element, however, the context in which the work is seen, is dependent on the market-clients, publishers, cultural institutions" (Roodenburg 6).

In the Ryerson Joint Program in Communication and Culture with York University my education has been influenced by the professors I have studied with, the courses I selected, my citizenship as a Canadian and my belief system, realized or not. Successful photographs should transcend banal reality and is its own subject. "Although the art world has become open to so many forms of photography, old and new, documentary photography still has a problem fitting into this context. Basically it is one of perception -the photographer's intentions, the issues raised in the work do not always come through in the context of museums, which excludes social reality instead of welcoming it" (Roodenburg 7). Within my work viewers may not share the same values, intention, nor perception may coincide. If the ideas of letting photographs speak for themselves is an attempt to make this situation palatable, it is proof of a great inability to adapt. Images do not speak for themselves, however; they are ambiguous, and intentions need a context to guide the viewer towards the photographer's intended interpretation. It can be argued that "it sounds like an honourable approach -being a democratic one -to allow the viewer and the consumer to interpret and use images entirely in accordance with their own 
needs; in practice however such an approach has the effect of gagging both the photographer and his work" (Roodenburg8)

Roodenburg presents an interesting argument that documentary photography as she understands it is an immigrant in the art world. This new freedom offers it room for experimenting with new forms, of the art, but this goes hand in hand with the loss of an old tie - that with a mass audience. The new context also means a change of identity. The images become works of art, with a new status; the intimate link between image and social reality. However, the photographer's vision, which is so essential for documentary photography, is pushed into the background as far as the average viewer is concerned. Roodenburg believes that documentary photography investigates and portrays aspects of contemporary reality, and in this sense it is related to the social sciences, I would venture that so too does some art photography relate to the social sciences for just as Roodenburg argues that documentary photography contributes to the social sciences on a philosophical meta-level and then a more concrete one so too can art photography (Roodenburg 9). My work at first glance may appear to be 'documentary' in nature, is not objective. There is no definitive truth of the real world but instead it is meant to generate questions about how reality is to be represented and how gender assumptions are made.

Another photographer who problematizes gender assumptions through photography is Della Grace whom has morphed into Del LaGrace Volcano. Her major work is Love Bites: Photographs, but her most current work with Sexmutant aims to radically question long held beliefs. Participating in the queer arts festival Sexmutant provides her with a 
platform for her work. She is a gender variant visual artist, also known as transgendered. For nearly twenty years she was known as Della Grace, lesbian photographer. In her work she pushed the parameters of what a lesbian could be. Volcano states that "I am a mutant and I always have been. I'm not the only one but let's face it, most people prefer stability, especially when it comes to gender. The binary imperative demands we make a definitive choice. One sex one body. Male or Female. Homo or Hetero. Yin and Yang ...specifically I have moved from a female location to a male location along the binary spectrum that is unfortunately very much in place" (Grace *). Through her work she critiques the concept of ghettoized arts practices and essentialist notions of gender and sexuality. Volcano's intention is to create an 'in-your-face' antidote for this form of global ignorance.

Evergon, a name known to most in the Canadian Photographic community is probably the most internationally recognized Canadian artist who explores gender-using photography. Since the early 90 's he has been documenting the fiction/action within work he entitles Manscapes. Subjects he explores are gay cruising grounds, truck stops, lovers' lanes, and beats. The National Gallery of Canada selected his work as part of Confluence and he regularly exhibits internationally. Evergon recently was awarded a Canada Council for the Arts ' $A$ ' grant to fund the continuation of his research into maleto-male rendezvous locations in non-Eurocentric countries. Evergon is currently Head of Photography at Concordia University, Montreal. Both he and Del LaGrace Volcano's work are evidence that gender identity and sexuality are still relevant issues to explore using photographic tools. His work is inspiring for he explores gender using photography in a way that is not overt. 


\section{The Lure and Challenge of the Darkroom}

Cartier-Bresson's description of what joy can be achieved when one masters an image also applies for the darkroom. "To take photographs means to hold one's breath when all faculties converge in the face of fleeing reality. It is at that moment that mastering an image becomes a great physical and intellectual joy" (Cartier-Bresson 16). There is an intense level of apprehension yet satisfaction when I work in the darkroom. I must deal with my decisions when I was in the field photographing. What I chose to keep in focus, what shutter I selected, and other split decisions all factor into creating the negatives from which I print while in the darkroom. My time in the darkroom can be a very soothing process, almost as if I would imagine being in my mother's womb. Yet, at other times, it is a roller coaster ride of emotions when a print does not become what I had envisioned.

Somehow my moment with my subject seems violated, not as pure, and questionable, for I did not master what my mind's eye was seeing and it will be forever lost to the outsider viewer.

For photographers, there are two kinds of selection to be made, and either of them can lead to eventual regrets. There is the selection we make when we look through the viewfinder at the subject; and there is the one we make after the films have been developed and printed. After developing and printing, you must go about separating the pictures which, though they are all right, aren't the strongest. When it's too late, then you know with a terrible clarity exactly where you failed; and at this point you often recall the telltale feeling you had while you were actually making the pictures. Was it a feeling of hesitation due to uncertainty? Was it because of some physical gulf between yourself and the unfolding event? Was it simply that you did not take into account a certain detail in relation to the whole setup? Or was it (and this is more frequent) that your glance became vague, your eye wandered off(Cartier-Bresson 25). 
Whatever printing technique I use, I cannot compensate for poor negatives; poor negatives technically or ones that just do not communicate on the level that I had hoped for. They are unforgiving. That is why, even to this day, I still am nervous when I process film for I am always anxious to see the results of a shoot. The process confirms I achieved what I had intended to capture or that I failed to learn from my mistakes. Sometimes, though, the sadness and disappointment when one misses the mark is so intense because one always realizes that the moment can never be recaptured. One may be able to recreate a close, shot but it is usually not better than what one first had hoped to secure.

\section{Criticizing and Interpreting Photographs}

"The photographer gives us images; the critic gives us words for the images (Barrett 21). By what standards do we judge the success or failure of a photograph? Photographs made in a straightforward, stylistically realistic manner are in special need of interpretation. They look so natural that they seem to have been made independently of a photographer. If we consider how these photographs were made, we may accept them as if they were made by an objective, impartial, recording machine. My knowledge, beliefs, values and attitudes-heavily influenced by my culture are reflected in the photographs I take. As Barrett maintains "each photograph embodies a particular way of seeing and showing the world. Photographers make choices not only about what to photograph but also how to capture an image on film, and often these choices are very sophisticated" (Barrett 36). 
Hans-Georg Gadamer, a European philosopher known for his extensive work on the topic of interpretation, says that to interpret is to "give voice to signs that don't speak on their own. To interpret is to account for all the described aspects of a photograph and to posit meaningful relationships between the aspects" (Barrett 37). Interpreting my own work is an exercise in expressing through words my meaning, the sense, the tone and/or the mood of the photographs I have created. I attempt to articulate in the most concise manner possible what my images are about. What my photographs signify to others is also interesting to me. Is the language (visual) in which I am working easily communicated and received by people or does one have to be prefaced with an oral or written description prior to viewing in order to convey the proper connotations? For a successful interpretation to be made an argument must have logic that leads to a potentially valid conclusion. Questions such as: what do these photographs represent? Are they supposed to mean something? What appears on the surface and what other layers can be examined with more time? According to Barrett, a respected Professor of Art Education with a concentration in Photography at Ohio State University, there are different frameworks from which work can be interpreted. Psychoanalytic, formalist, semiotic, Marxist, interpretations based on stylistic influences, biographic interpretation, intentionalist interpretation, interpretation based on technique or a hybrid of approaches (Barrett 45). Interpretations are not so much true or false as plausible and implausible. When being aware of the criterion of the interpretative framework it aids in preventing the arguments from being too subjective and allows an interpretation to be back by a particular type of evidence for a certain understanding of a photograph. "By relying on or waiting for a photographer to explain his or her intents, we are abnegating our responsibility of 
interpreting what we see. When a photographer does offer particular interpretations of specific images or general interpretation that apply to his or her work, that interpretation becomes one among many possible or actual interpretations" (Barrett 51). As Adams states in his essay 'Civilizing Criticism' "as the years pass I hope that critics will also drop the heavy academic machinery as is consistent with getting at the truth. Elaborate ideational schemes for interpretation, such as psychoanalysis, tend generally to lead away from the photographs and in the process to oversimplify what is mysterious and of greatest value in the work" (Adams 55).

Leading photographic critic Vicki Goldberg pulls no punches in the preface of her book 'Light Matters: Writings on Photography' when she states; “Art in general is floundering right now, too often neither addressing matters crucial to society in any meaningful way nor affecting the heart. Photography, having achieved parity with other art forms, suffers the same malaise" (Goldberg 18). Photography can fight this spiral into irrelevance by providing an environment for exploration of issues that are paramount to our understanding of us. Gender and sexuality are topics that affect everybody no matter how one identifies them. Just as academics debate theorists' papers and assertions, so too can the art world critique photographers' approach to these areas of interest. 


\section{Conclusions}

My work does not have one single position. I maintain that I am a postmodern feministphotographer. Postmodernists do not have to be rigid in their beliefs for there is no universal truth of photographic art that need to be followed. In affirming my interest in qualities unique to photography it may be said that I am placing myself at a distance from postmodernists but this distance is acceptable. The notion that photographs are objective observations is problematic. The paradigmatic selection within a photograph may reveal particular discursive strategies and ideologies at work. Factors such as cultural background, social status, religious beliefs, and level of comfort with ones own sexuality influence how any viewer would interpret a still image. Furthermore, the context in which the image is viewed also shapes the reading. A photograph is an interpretation by the photographer and so is subject to various acceptable readings. The interpretative photographs I created "are personal and subjective interpretation, more like poetry than a scientific report." My indicators are not going to provide direct imperial evidence but instead my photographs are inferences, as my research is qualitative not quantitative. Acknowledging that "photographs and film are representations and not the embodiment of truth or objective reality, but that is how they affect us: the images and soundtrack overwhelm us, as it were, and make it difficult for us to remain impartial, distanced and critical" is necessary (Van Vree 58). Ways I can refine or constrain my definitions to strengthen the inferences that I will draw would be to clearly state my perceived cultural and ideological beliefs, for example. 
Appendix A

\title{
Looking at my own photographs
}

\author{
Doreen Sparling and Sylvia Howes \\ Photographed in Worthington, Massachusetts, USA
}

Row One-Image (1A) Is taken outside on an autumn day as fallen leaves line the path of the woods. Two people are walking along a path with a dog in front of them. The subject on the left wears a Celtics winter coat, jeans and running shoes. The subject on the right wears a knitted coat with a nature scene on it, also in jeans, and in walking shoes. The path moves towards the horizon line and one might wonder where the path leads as the dog appears to be walking ahead with purpose. One can see that the natural surroundings these subjects appear to be walking in are not untouched by man as an electrical pole and wire can be scene in the highlighted area of the sky.

Row One-Image (2B) Continuing on their walk it appears the dog is seen off the path and the people appear to be waiting for it. The eye into two triangles can almost divide the image with the top being the forest with the dog and the lower half being the path with the people standing in the highlights.

Row One-Image (3C) In the shaded part of the woods slightly off the road, the subject in the Celtics coat appears to be playing with the dog while the other individual looks on from inside the forest line. One might wonder why the one woman was so far off the path? What caught her eye and why did the other person not follow her?

Row One-Image (4D) This shot captures the motion of the woman walking after the dog and towards the other woman. The dog appears to be seeking the stick being held by the subject on the left. The dog has a visible collar on which suggests that the dog is owned by someone possibly one of these people or both? The photograph is shot a slight diagonal with the top half above the diagonal lined with tress and the lower half being the forest floor.

Row One-Image (5E) As one follows the path in this image one sees the subject in the Celtics coat walking up the path which is a on a slight incline towards car. The Subaru has Massachusetts' plates and a rack on the top of it. The woman by the car is reaching for the car door and appears to be about to open it possibly to allow the dog inside. Looking into the highlighted area one can see that there is some sort of building in the right of the frame possibly a barn of some sort. The tonal range also suggests that there is quite a difference between the shaded forested area and the outer region. 
Row One-Image (6F) Inside a house this image was taken in the evening or early morning from the darkness of the windows. Cut outs of cats are adhered to the window and the dog is at the table to appearing to be waiting for something. One woman appears to be serving the other two women some food. The woman who was in the Celtics coat appears to be the oldest at the table, by looking at her hands. There is an additional . woman in this shot that can only be seen from behind. One cannot tell what she is really doing but appears to be most likely waiting for the woman standing to serve her. An additional place setting appears to be in the most left hand corner of the table. Four photographs are on the side of the fridge but it is hard to distinguish what they are of. Two appear to be nature scenes while the photograph in the top right is of a North American football player. When looking at the left side of the photograph one can see a frame photograph on the wall that is hard to make out along with painting of two people in a canoe in a natural environment on a bookcase. The lamp is also decorated with silhouettes of leaves,

Row One-Image (7G) Inside a house this image was taken in the evening or early morning from the darkness of the windows. Cut outs of cats are adhered to the window. The three subjects in the kitchen were photographed from a slightly different angle and cropped more tightly. Both the two women facing the camera appear to reflecting on something while holding their mugs. There are a few plates on the table but otherwise the meal seems to be winding down. The subject whose face we cannot properly see appears to be looking at the woman on the right. One can see that there is a fourth chair, which is empty, and one wonders if someone was sitting there at one time. Does the wine glass by the windowsill belong to a person who is missing from the frame or placed there by one of the three women at the table?

\section{Gillian McMillan and Michael Dietel Photographed in Toronto, Ontario, Canada}

Row Two-Image (1A) Here a man and women stand extremely close to one another. The woman has her head slightly tilted and the man has his eyes closed. They appear as if they are about to kiss. The room in which they are in is rectangular in shape with plain walls. To the right of the frame there are two hanging objects one appears to be something in a frame the other indistinguishable. To the left in front of the subjects is a bench press with weights ready to use as well as some additional weights on the hardwood floor. Illuminating the room there are two light sources. The one visibly lit on the floor and one from above which is most likely turned on by pulling the beaded string hanging down slightly to the left of the subjects' heads. The mattress resting against the wall creates another shadow behind the pair. Looking along the wall that the mattress rests on one can see three unlit lamps. Looking at the top of the frame the line of the wall slopes down which draws the eye into the corner we cannot see of the room. One can only guess where it leads. 
Row Two-Image (2B) A second photograph of the pair shows that they have progressed into an embrace with the male's arm wrapped around the woman as they kiss. The lighting is slightly darker than in (2-1A). The increased shadows allow the eye to focus more on the couple rather than the surroundings. The framing of the image is also slightly tighter.

Row Two-Image (3C) Shot from a worm's eye view. The couple is seen standing at a counter of a restaurant. The restaurant is Asian, but from looking at the menu one cannot read what is offered. The man stands slightly left and behind of the woman with his right arm resting on her lower back. The woman rests her right hand on the counter and is looking slightly left. Perhaps she is looking at a person behind the counter or a something else that captures her attention in that corner. Another woman is behind the counter peeking around the stacked takeaway bowls. The Coke fridge on the left along with the stacked cans of pop helps create a leading line towards the subjects. The stacked take away containers and bowls do the same on the right side of the frame. The checkered floor also draws attention to the couple. The only light source in the frame appears to be from the overhead florescent lighting.

Row Two-Image (4D) This frame is significantly closer than (2-3C). The couples are in the centre of the frame and our facing towards the entrance of the restaurant having moved past the take away counter. The light source is the same but the objects that are along the wall on both sides are easier to view. On the left wall of the frame several frames and plaques are hung: one framed article from the Globe and Mail is the most visible. Safety tips are posted on the Coke machine along with the top of the machine used to store various items. On the right of the frame one can see a letter tacked onto the wall appearing formal in layout with the content is unreadable.

Row Two-Image (5E) This frame taken at the same angle and distance as (2-4D) shows the couple kissing in the restaurant. The man is leaning into the woman with his eyes closed and the woman has a slight smile on her face while her eyes are closed. Their hands are clasped. It appears as if she is leaning into the takeaway bowls from this angle.

Row Two-Image (6F) Shot from outside on a diagonal angle it can be seen that the restaurant is Sue's Thai Food Restaurant and Fish and Chips. The window sign boasts the best fish and chips along with two newspaper articles that appear identical, but are hard to distinguish. The sign on the street advertises an open patio and the phone number to order take-away. The couple exits the restaurant; the woman is holding the food as she looks back into the restaurant, possibly at the staff that served her. The man is following her closely.

Row Two-Image (7G) The couple is outside on a street that seems empty walking towards the Turner and Porter hand in hand. The woman holds the food while the man appears to hold a can of some sort. One can see that the woman's head is turned in the direction of her partner as the couple walks on the sidewalk. They are viewed from behind and are illuminated by the light from the Turner and Porter awnings. 
The street on the right side of the frame and the buildings on the left create leading lines that draw the viewer's attention to the subjects in the frame and to where they may be walking.

\section{Vince Tedesco \\ Photographed in Toronto, Ontario, Canada}

Row Three-Image (1A) A man can be seen down an aisle of a grocery store walking away from his cart in the lower left portion of the frame. One can only wonder as to what he is looking for and what final selection he will make. One can see the store is a Dominion because the shopping cart has their latest advertising campaign as well as labels along the shelves advertising bonus air miles. Advertisements hang from the sealing, line the shelves, and are on the floor. A cart appears to be left in the centre of the aisle. It is hard to see what is in the shopping cart it looks like boxes not groceries. Perhaps, a store employee left the cart there? Looking through the aisle, which is lit by florescent lights in the ceiling, the eye is drawn to the open 24 hours sign and the store employee behind the counter. She is looking to the left of the frame, not at the subject. Behind her the window is full of bright light indicating daytime.

Row Three-Image (2B) A man can be seen through the glass pushing a cart full of bags. He appears to almost blend into the glass in the top right pane. Along the door one can read the 'CAUTION STAND BACK' label. Inside the store are many items some distinguishable for example, the garbage, others almost as if a blur. One can also see on the outside of the right pane of glass there is another caution sticker (circular), opposite is an air miles logo sticker. To the right of the caution sticker is a square set of instructional stickers tops required, no bare feet, no pets except for seeing eye dogs and no roller blades. Outside of the door one can see a shopping cart in the lower right comer and a second garbage in the lower left. The light on the door from the left of the frame suggests a fairly brightly lit day.

Row Three-Image (3C) The subject is in the centre of the frame removing an item from a bag. His table appears to be a catch place for objects with some grocery products on the table along with a George Foreman Grill. Something circular can be seen in the bottom of the shot, possibly a lid of some sort. Looking in the left corner of the frame one sees his sink area and fridge, which he also uses a place of storage for, items such as cereal and crackers. On the fridge in a haphazard fashion are snapshots of himself with male friends, himself in costume, and postcards. A bill also seems to be tacked onto the fridge. Looking into the room one is aware of the low ceiling and the small windows allowing natural light into room. Two other lights offer artificial light. In the right middle section of the frame, in the shadows are framed images as well as a bar, table and a director's chair. Cards on the right windowsill appear placed on the windowsill for display while the window in the centre of the frame looks as if it is just used for storage. 
Row Three-Image (4D) This photograph is taken through a window. One can see the frame of the curved window in the lower left section of the photograph as well as the reflection on the left of the subject. The subject is looking into his bag and appears to be in the process of removing something due to the positioning of his hands. His table appears to be a catch place for objects with some grocery products on the table along with a George Foreman Grill. Below the table there are several bags most likely filled with groceries to be unpacked: In the right of the frame one can see a fireplace and a door with a circular sign on it. What looks like a square cut out in the wall holds the flat screen television. Another door near the centre of the frame is illuminated by natural light. The fridge is only seen partially due to the window frame, but one can see he also uses the top as a place of storage for, items such as cereal and crackers. On the fridge in a haphazard fashion are snapshots of himself with male friends, himself in costume, and postcards. A bill also seems to be tacked on the fridge. Looking into the basement apartment one is aware of the low ceiling and the small windows allowing natural light into room. Two other lights offer artificial light.

Row Three-Image (5E) In this photograph one can see the subject leaning on a car with his hands crossed, sunglasses on, waiting for someone. A woman exits 179 with a smile on her face. What is between them is a covering for an establishment but there is no visible sign allowing the viewer to determine what it is. The sun is bright in the shot and the temperature may be warm as the woman is in a sleeveless top and a man walking towards the pair has what looks like a jacket thrown over his shoulder. The space pavement in the foreground has many oil stains suggesting that cars park in that location in addition to the street.

Row Three-Image (6F) The subject in this frame is seen in the left half of the frame looking intently at a man who has a beer in his hand. Along the right wall of the room two females appear to be in a conversation. A poster of Natasha Bedingfield hangs from the top corner of the frame. The arm looks like it is protruding out of the poster. Below the poster is a bar fridge with empty glasses on it, and a purse. Adorning the walls of this room are several photo collages and snapshots. A door leading out of the room has a security lock, which suggests that not just anyone can gain access to this room. An empty chair sits between the women and men and a second one behind the subject. Pot lights illuminate the room as well as the flash of the photographer seen reflected in the glass frame above the women.

Row Three-Image (7G) Photographed from a bird's eye view one can see the emotion clearly in the shot. A man is standing, beer in hand, smiling while looking at something outside the frame. A woman sitting in the chair is smiling widely with her arms raised as if she is cheering about something. The subject in the centre of the frame grinning while sitting in a chair with his hands raised in the air. Adorning the walls of this room are several photo collages and snapshots. A signed poster by Natasha Bedingfield hangs in the top corner of the frame and looks as if she is gazing out of the frame. Below the poster is a bar fridge with empty glasses on it, and a purse. In the right lower corner of the frame is a person's leg, (most likely female). 


\section{Eva Choy \\ Photographed in Toronto, Ontario, Canada}

Row Four-Image (1A) In this photograph one can see the subject, a young woman, exiting from 179 smiling as she looks at something outside of the frame. Taking up a significant portion of the left side of the frame is a covering for an establishment but there is no visible sign allowing the viewer to determine what it is. The sun is bright in the shot and the temperature may be warm as the woman is in a sleeveless top and the shadows indicate strong sunlight.

Row Four-Image (2B) Shot on a slight angle this photograph shows the subject interacting with a sales associate from Footlocker. The woman is trying on a pair of Converse sneakers and the sales associate is helping her with the laces. The slight blur of her right hand indicates that she is moving towards the shoe while she firmly holds her purse in her left hand. The sunlight beams through the windows almost creating a silhouette. Different types of shoes and athletic wear line the walls and the display window. Other customers surround the subject. One male is looking at the wall of men's shoes with his back to the camera. A girl in a black tank top and sunglasses on her head is inspecting an item with her hands. Just out of the frame is another person but only one arm is visible. Behind the subject is a blond girl sitting looking at something in the right corner of the frame. Taking up a third of the frame along the right side is a door, which possibly leads to the stock room.

Row Four-Image (3C) With a footlocker shopping bag in the subject's left hand she walks through an alley talking on her cell phone. The wall she is walking in front of is full of graffiti along with the door of the building. Looking towards the right corner litter can be seen on the ground and piled in a corner. The curb provided a leading line, the building creates a strong form, and the left edge is framed by another building one cannot see much of but one can see it is also has graffiti.

Row Four-Image (4D) The subject in the scene is reaching for something under the bar, which runs diagonally across the lower portion of the frame. The bar is wet and appears to be of a rough surface. Revival, the name of the establishment can be seen almost positioned under the subject. Just protruding into the frame on the left side is a person's arm. As one makes one's way from the left side of the photograph towards the subject one can see another female in the midst of cleaning as she holds a tray. Two poorly lit subjects, a male and a female, drink in the shadows. Besides the subject a young man leans towards the bar directing his gaze towards something outside the frame, almost as if something is causing him concern. The subject looks as if she is not looking at anything in particular, almost as if she is in her own thoughts. Behind her is a person looking down towards the till. Behind the subject is a man in a Led Zeppelin t-shirt, stained jeans, and a baseball hat. His arms crossed he gazes outside of the frame but with a look of concentration. To the right of the frame are beer taps for draft beer. Hanging down from the ceiling are decorations that are very reflective along with garland that lines the curved wall behind the bar. The bar wall is lined with bottles. 
Row Four-Image (5E) The subject is centered in the frame and seen to be leaning over the bar engaged in an exchange with a man who is holding a drink. Watching behind the subject is a blond man who has his eyes on the man across the bar. In the background between the subject and the man, is also another person whose head is blocked by the beer taps. It is not possible to determine what the person is engaged in. Behind the bar one can see a Corona box along with many bottles of liquor. The television screen advertises Premium cigarettes for sale.

Row Four-Image (6F) The subject is smiling broadly in this photograph. She is holding a hose in her right hand as she moves down the bar. The bar seen along the lower right of the frame and creates a strong diagonal leading line. Behind the subject one can see two individuals, a woman in a short skirt looking slightly apprehensive at something outside the frame and two males who are in the shadows. Another male is in the mid area of the right portion of the frame but has their back to the unfolding scene.

Row Four-Image (7G) The subject is in motion in this scene holding a purse in her right hand. To the left of her, is woman counting money as well as a male counting money. Walking in front of her towards the empty chair is a tall man who is in the midst of lighting a cigarette. The same man who was behind her in (4-5E). Three other individuals are seen, in the scene two drinking beer and one woman looking at something in her hand. Parts of a drum set are on the sofa in front of the drapes. Many frames adorn the wall filled with snapshots and photographs. A person in a winter coat is entering the scene on the left side of the frame.

\section{Fabio Persico}

\section{Photographed in Pickering and Toronto, Ontario, Canada}

Row Five-Image (1A) The male subject in this photograph has his hand in his pocket as he waits for his drink at the counter of a Second Cup. The girl to the left of him appears to be making his beverage while the girl to the right of him watches him. The light shining through the windows is bright and reflects in the display case at the front counter. Artificial lights also illuminate the coffee shop. According to the clock it is around 10:18 in the morning. There appears to be no other customers in the shop from the angle the shot was taken. The tables in the foreground are empty and clean.

Row Five-Image (2B) - The subject can be seen to the left of the frame engaged in a conversation with a female. Both have scarves around their necks, which could indicate the weather has turned cold. Both are sitting in front of an empty table and look relaxed. One can see the female's coat with fur lining on her seat along with a canvas bag leaning up against her chair. An empty sofa is in the lower left corner of the frame as well as an empty chair in the lower right. Behind the subject is a framed three-dimensional piece, and along the wall behind the female is a fireplace used to display items from the shop. 
Row Five-Image (3C) The subject is walking out of the Second Cup coffee shop in the centre of the frame. The door is being held open for him by the same female that was sitting with him inside the shop in image (5-2B). An onlooker in a long black coat watches them exit the shop. Snow is on the ground indicating winter and the reason for the scarves draped around both the male and female's necks. Both have their coats open so it may not be extremely cold. Several businesses are in the background: City Cleaners, A Dentist, Deja VuDics, Supercuts and Shoppers Drugmart.

Row Five-Image (4D) In this photograph the subject appears to be enjoying whatever game he is playing on the Megatouch 2006 ION. Behind him a young man is smiling while looking at something out of our view. What appears to be a heavy set woman is having a cigarette in the shadows behind the subject and to the lower left of the frame what looks to be a person's shoulder or back is protruding into the frame. A bottle of Rev and the top of another bottle can be seen in the bottom of the frame. As one moves to the right side of the image one can see a can of Red Bull on display behind glass, as well as an assortment of bottles of liquor. Lining the wall of the establishment are framed posters of boats from a particular time period. Beads and garlands hang from the ceiling. The railing of the bar acts as a leading line diagonally dividing the two halves of the photograph into two loose triangles.

Row Five-Image (5E) This photograph is taken from a similar angle to 5-4D but from a farther distance. The subject is seen to be laughing at something that amuses him while the people he is beside also react. The man in the foreground is laughing as well while he holds on to the railing of the bar. What appears to be a female has her head bent almost touching the bar and the young man behind the subject is taking a drag of his cigarette looking quite relaxed. Along the bar it can now be seen that an empty bottle of Smimoff was next to the Rev. Items such as an ashtray, a small purse, a package of cigarettes and a full martini also line the bar. On the railing of the bar appears to be another purse. One can see no one else in the frame except for a jacket protruding in the corner so one may wonder whose items are along the bar. One can see more of the bar in behind the glass in this frame, which suggests that perhaps the subject is in a particular section of the bar that allows smoking.

Row Five-Image (6F) Within this frame one can see the subject leaning back in laugher as he watches the female make a motion on the floor which could be dancing. Whatever she is doing also amuses the two other males on either side of the subject as well as the two men in the shadows. The young man with the cigarette is also watching the scene unfold as he takes a drag of his cigarette. Two other people are interacting with each other, oblivious to the scene unfolding. A person's leg can be seen in the lower right hand corner of the photograph with a scarf resting on it. With the positioning of the knee there is a strong likelihood that the person is also watching the scene. Above the subject's head is a television and to the left of that exits sign above an emergency door. One can also see that the framed posters of boats continue around the back wall of the establishment. 
Row Five-Image (7G) This image taken from a slightly bird's eye view shows the subject surrounded by a group of people. To the immediate left is a female whose face cannot be seen. To the right is the female who was in both (5-5E) and (5-6F) communicating with the young man who was smoking in the shots (5-4D), (5-5E), and (5-6F). Looking at the subject is another male seen laughing in (5-6F). To the right is an empty barstool possibly an extra from the table or belonging to another one? To the left of the group is an older man looking towards the direction of the photographer with a pack of cigarettes and a loose one in hand. One can also see that the framed posters of boats continue around the back wall of the establishment.

\section{Erin Bentley and Kimberly Photographed in Toronto, Ontario, Canada}

Row Six-Image (1A) The scene is outside in low light. From the left of the frame one sees the subject, hand in pocket, smiling, as she watches the dog walk around. The woman in the centre of the photograph appears to be interacting with the dog as she smiles also. In the background one can see office towers and apartment dwellings. Cars line one side of the street as well as in a parking lot across the road. The impression is that the people are with their dog in a city. Looking above one of the trees is may be the $\mathrm{CN}$ tower through the trees.

Row Six-Image (2B) The scene is outside in low light. The grass that the subjects are standing on with their dog is surrounded by road. One can see apartment buildings behind them and a pedestrian walking along. The couple appears engaged in a happy moment with both smiling broadly and looking relaxed.

Row Six-Image (3C) The scene is outside in low light. One can see the one subject laughing as the other woman places her head on her chest. The dog is nearby.

Row Six-Image (4D) The subject can be seen holding another person's hand while smiling at a woman to the left of her. Shot from a worm's eye angle one can see three other people who appear to be guests of the table and other patrons in the background. The tables shot on a diagonal provide a separation visually between those really participating in the scene and those in the background or off to the side. Looking at the table one can see that the majority of drinks are empty and plates of food picked through so perhaps the scene unfolds at near the end of the meal.

Row Six-Image (5E) The subject is seen to be entering a women's washroom in a public place. No other markings identify the location as the walls are plain and the ceiling looks like an industrial ceiling. The walls do add depth to the scene.

Row Six-Image (6F) In this photograph the subject is holding the door open for someone that is outside the frame. The subject has sunglasses on their head and a leather coat, 
which could indicate that the subject is about to go outside. In the background two people are leaning against the reception desk speaking with what appears to be a building official, possibly the security for the building. The bright sunlight is streaming into the building and reflecting off the floor.

Row Six-Image (7G) Two people in a corridor inside a building. The floor is carpeted and they may be waiting for an elevator or looking at something between them. They have coats on so they could be heading outside or just have come in. The florescent light in the ceiling provides some light, but not as much as the natural light from behind the two people. 


\section{Bibliography}

Adams, Robert. (1994) Why People Photograph, New York: Aperture Foundation, Inc.

Adams, Robert. (1996) Beauty in Photography: Essays in Defense of Traditional Values, New York: Aperture Foundation, Inc.

Ang, Tom. (2000) Picture Editing, London: Oxford: Focal Press.

Ballerini, Julia. (ed) Sequence (con)sequence: (sub) Versions of Photography in the 80s, New York: Aperture Foundation, Inc. (1989)

Barrett, Terry. (2000) Criticizing Photographs: An Introduction to Understanding Images Third Edition, Toronto: Mayfield Publishing Company.

Bech, Henning. (1997) When Men Meet, Chicago: University of Chicago Press.

Birdwhistell, Ray L. (1975) Background Considerations to the Study of the Body as a Medium of Expression. In Jonathan Benthall and Ted Polhemus, (eds), The Body as a Medium of Expression. (p.36-58). London, England: Allen Lane.

Burgin, Victor. (1982) Photographic Practice and Art Theory. In Victor Burgin (ed) Thinking Photography (39-83). London: The Macmillan Press Ltd.

Callen, Anthea. (1995) Ideal Masculinities: An anatomy of power. In Nicholas Mirzoeff (ed.), The Visual Culture Reader $2^{\text {nd }}$ Edition. (p.603-616). London, England: Routledge Taylor \& Francis Group.

Cartier- Bresson, Henri. (1999) The Mind's Eye, New York: Aperture.

Delius, Peter and Jacek Slaski (ed). (2003) Women by Women: Erotic Photography, Munich: Prestel.

Ellis, John. (1982) Visible Fictions: Cinema, television, video, London, Routledge..

Foucault, Michel. (1980) Power/Knowledge: selected interviews and other writings 19721977 (ed. Gordon, C.) New York, Pantheon Books.

Foucault, Michel. (1990) The History of Sexuality An Introduction: Volume 1. New York, Vantage Books.

Foucault, Michel. (1970) The Order of Things, London, Tavistock.

Frank, Robert (1985) Robert Frank and American Politics. Ohio: Arkron Art Museum. 
Garb, Tamar. (1994) The Forbidden Gaze: Women Artists and the male nude in the late nineteenth-century France. In Nicholas Mirzoeff (ed.), The Visual Culture Reader $2^{\text {nd }}$ Edition. (p.617-624). London, England: Routledge Taylor \& Francis Group.

Goldberg, Vicki. (2005) Light Matters: writings on photography, New York: Aperture.

Hall, Stuart. (2002). Representation: Cultural Representations and Signifying Practices. London: SAGE Publications.

Harley, John. (2002) Communication, Cultural and Media Studies: The Key Concepts, Third Edition. London, Routledge.

Jay, Bill and David Hurn. (1997) On Being a Photographer- A Practical Guide- David Hurn (Magnum) in conversation with Bill Jay, Portland: Lens Work Publishing.

Jay, Bill and David Hurn. (2000) On Looking at Photographs - A Practical Guide- David Hum (Magnum) in conversation with Bill Jay, Portland: Lens Work Publishing.

Jones, Amelia. (1998) Dispersed Subjects and the Demise of the 'Individual' 1990s bodies in/as art. In Nicholas Mirzoeff (ed.), The Visual Culture Reader $2^{\text {nd }}$ Edition. (p.698-710). London, England: Routledge Taylor \& Francis Group.

Jussim, Estelle. (1989) The Eternal Moment: Essays on the Photographic Image, New York: Aperture Foundation, Inc.

Kuhn, Annette. (1985) The Power of the Image. London: Routledge.

Lober, Judith. (1996) 'Beyond the Binaries: Depolarizing the Categories of Sex, Sexuality, and Gender.' in Social Inquiry Vol. 66. (p.143-159). Austin: University of Texas Press.

Loshitzky, Yosefa. (2003) 'Afterthoughts on Mulvey's "Visual Pleasure" in the Age of Cultural Studies'. In Elihu Katz ... (et al.), Canonic Texts in Media Research: are there any? should there be? how about these? (p.248-259). Cambridge, England: Blackwell Publishers.

MacRae, Donald G. (1975). The Body and Social Metaphor. In Jonathan Benthall and Ted Polhemus (eds), The Body as a Medium of Expression. (p.59-73). London, England: Allen Lane.

McNay, Lois. (1992) Foucault and Feminism: Power, Gender and Self. Boston: Northeastern University Press.

Mercer, Kobena, (1994) 'Reading racial fetishism' in Stuart Hall (ed). Representation: Cultural Representations and Signifying Practices. (p.285-290). London: SAGE Publications. 
Metcalf. Andy and Martin Humphries.(1985) The Sexuality of Men, London, Pluto Press.

Metz, C. (1985) 'Photography and fetish', October, Vol. 34 (Fall).

Miller, Denise.[et al.] Photography's Multiple Roles: art, document, market, science. Chicago: The Museum of Contemporary Photography, Columbia College; New York Dap, Inc., (1988).

Mulvey, Laura. (1975/1989) 'Visual Pleasure and narrative cinema', Indiana, Indiana University Press.

Mulvey, Laura. (1981) Afterthoughts on 'Visual Pleasure and Narrative Cinema' Inspired by King Vidor's Duel in the Sun (1946). In Laura Mulvey, Visual and Other Pleasures (p.29-38). Indiana: Indiana University Press.

Mulvey, Laura. (1987) Changes: Thoughts on Myth, Narrative and Historical Experience. In Laura Mulvey, Visual and Other Pleasures (p.159-176). Indiana: Indiana University Press.

Neale, Steve. (1983) 'Masculinity as spectacle' in Stuart Hall (ed). Representation: Cultural Representations and Signifying Practices. (p.331-333) . London: SAGE Publications.

Nestle, Joan. (1984) 'The Fem Question' in Carole S. Vance (ed). Pleasure \& Danger: Exploring Female Sexuality. (p.232-241). Boston: Routledge \& Kegan Paul.

Nixon, Sean. (1997) Exhibiting Masculinity in Stuart Hall (ed). Representation: Cultural Representations and Signifying Practices. (p.291-330). London: SAGE Publications.

Perniola, Mario. (1985) Between Clothing and Nudity. In Michel Feher (ed.), Fragments of the Human Body, Part Two. (p.237-265). New York: Urzone Inc.

Polhemus, Ted. (1975) Social Bodies. In Jonathan Benthall and Ted Polhemus (eds), The Body as a Medium of Expression. (p.13-35). London, England: Allen Lane.

Richards, Eugene. (1994) American We, New York: Aperture Foundation, Inc.

Richards, Eugene. (2000) Dorchester Days, London: Phaidon Press Ltd.

Rooswnburg, Linda. (1997) PhotoWork(s) in Progress/Constructing Identity, Rotterdam: Nederlands Foto Instituut.

Rose, Gillian. (2001) Visual Methodologies. London, Sage Publications. 
Sekula, Allan. (1975) On the Invention of Photographic Meaning. In Thinking Photography (p.84-109). London: The Macmillan Press Ltd.

Shore, Stephen.(1998) The Nature of Photographs, Baltimore: The John Hopkins University Press.

Terreehorst, Paulina. (2002) Shaken not Stirred. In Frits Gierstberg and Warna Oosterbaan (eds), The Image Society: Essays on Visual Culture (p.22-33). Rotterdam: NAi Publishers.

van Vree, Frank. (2002) The Sensation of the Image: On the Visualization of Historical Culture. In Frits Gierstberg and Warna Oosterbaan (eds), The Image Society: Essays on Visual Culture (p.56-67). Rotterdam: NAi Publishers.

Volcano, Del LaGrace and Evergon. "Sexmutant." 2000.

$<$ http://www.sexmutant.com/contents.htm> 